\title{
ANÁLISES E REFLEXÕES AFROCÊNTRICAS ACERCA DA EDUCAÇÃO FILOSÓFICA
}

\author{
Katiúscia Ribeiro* \\ Valter Duarte Moreira Jr. **
}

\begin{abstract}
RESUMO: De acordo com o filósofo afro-americano Molefi Asante, a anterioridade das civilizações clássicas africanas deve ser considerada em qualquer pesquisa que busque discutir o desenvolvimento dos fenômenos culturais africanos. Denotando, a falta desses pontos de referência, uma desconexão e descontinuidade histórica. No presente trabalho pretendemos fazer um levantamento bibliográfico qualitativo sobre a produção acadêmica de filosofia, investigando os efeitos da recepção do conceito de Afrocentricidade pelos profissionais dessa área de ensino no Brasil, sua utilização como ponto de partida para problematizar a permanência do pensamento racista e colonial reproduzido nos ambientes educacionais, refletindo a partir disso sobre o paradigma da Afrocentricidade como uma forma de enfrentamento dos fenômenos complexos do Racismo Epistêmico e do Epistemicídio, seguindo a esteira de diversas especialistas de diferentes áreas do ensino.
\end{abstract}

PALAVRAS-CHAVE: Filosofia; Afrocentricidade; Kmt.

\begin{abstract}
According to the African-American philosopher Molefi Asante, the precedence of the African classical civilizations should be considered in any research stablished to discuss the development of African cultural phenomena. In which the lack of these points of reference indicates a disconnection and a historical discontinuity. In this paper we aim to make a qualitative bibliographic on philosophy academic production, investigating the effects of Afrocentric concept reception by the professionals of this area of education in Brazil, its use as a starting point to problematize the permanence of racist and colonial thought reproduced within the educational environments, reflecting from this about the Afrocentric paradigm as a way to get the Epistemic Racism complex phenomena, following the trail of several scholars on this matter.
\end{abstract}

KEYWORDS: Philosophy; Afrocentricity; Kmt

\section{Filosofia e Educação}

No recorte deste trabalho, refletiremos sobre a afrocentricidade como forma de

\footnotetext{
* Doutoranda em Filosofia pela Universidade Federal do Rio de Janeiro, Mestra em Filosofia e Ensino pelo Centro Federal de Educação tecnologia Celso Suckow da Fonseca, CEFET/RJ (2017). Graduação em Filosofia pela Universidade Federal do Rio de Janeiro (2013). Bolsista da Coordenação de Aperfeiçoamento de Pessoal de Nível Superior - Brasil. E-mail: kemetic@ymail.com / katiusciaribeiro@yahoo.com.

** Doutorando em Filosofia pela Universidade Estadual do Rio de Janeiro, Mestre em Filosofia pela Universidade Federal de Sergipe (2016), Graduado em Filosofia pela Universidade Federal de Sergipe (2014). Bolsista da Coordenação de Aperfeiçoamento de Pessoal de Nível Superior - Brasil. E-mail: valtermoreiraz@gmail.com
}

enfrentamento aos fenômenos complexos do Racismo Epistêmico ${ }^{1}$ e do Epistemicídio ${ }^{2}$. O termo "filosofia", quando utilizado para se referir à faculdade humana da razão, pode ser traduzido como o ato de pensar, criticar, educar, refletir. "Educação", por sua vez, refere-se ao método pelo qual o ser humano adquire conhecimento, e ao com-

\footnotetext{
${ }^{1}$ Por esta expressão conceitual referimo-nos a um conjunto de dispositivos, práticas e estratégias produtoras de cânones que excluem a produção cultural e filosófica de matriz não-europeia.

${ }^{2}$ Por Epistemicídio referimo-nos a um conjunto de práticas e discursos de poder que impetrou uma desqualificação estética, ética, intelectual e espiritual em todos os povos não europeus.
}

RIBEIRO, Katiúscia; MOREIRA JR., Valter Duarte. Análises e reflexões afrocêntricas acerca da educação filosófica. Revista Sul-Americana de Filosofia e Educação. Número 31: mai.-out./2019, p. 8710o. DOI: https://doi.org/10.26512/resafe.vi3o.28258 
promisso de possibilitar ao aluno a reflexão sobre temas inerentes a sua existência. $\mathrm{O}$ Dr. em filosofia Djalmo Medeiros nos traz reflexões relevantes sobre a questão. Segundo ele, a filosofia na sala de aula exerce o papel importante na construção do sujeito, responsabilizando por completo o professor nesse processo, "os educandos vão se transformando em reais sujeitos da construção e da reconstrução do saber ensinado". (MEDEIROS, 2015, p. 75). Assim, cabe ao professor a ressignificação do saber através de elementos curriculares capazes de promover um despertar positivo na vida desses estudantes. A principal característica da filosofia está no estudo e exercício desse despertar. A capacidade de pensar infinitamente permite ao estudante compreender o incompreensível.

Medeiros nos traz a reflexão de Paulo Freire, que vislumbra na educação não apenas a capacidade de transferir conhecimento, mas criar a possibilidade para a produção e/ou a construção do mesmo. O processo de aprendizagem não está apenas embutido no aprender, mas no processo de deflagrar na pessoa aprendiz uma curiosidade crescente, que permite torná-la mais e mais criadora. O que se quer dizer é: quanto mais criticamente se exerce a capacidade de aprender, tanto mais se constrói e se desenvolve a assim chamada "curiosidade epistemológica”, sem a qual o conhecimento cabal do objeto não pode ser alcançado (apud MEDEIROS, 2015, p. 75).

O que nos diz Medeiros pela ótica de Freire é que, quanto mais críticos formos, melhor será nossa capacidade de percepção sobre o que nos cerca. Ao despertar o senso reflexivo, validamos na prática o ensino de filosofia. É possível perceber nessa apresentação de Medeiros a importância do ensino de filosofia e a preocupação de tornar o indivíduo crítico, capaz de julgar e avaliar a construção de seu pensamento.

De acordo com a concepção hegemônica de "conhecimento", demarcada pelo crivo eurocêntrico, postula-se a produção europeia como universal e superior ao crivo dos outros povos. Tal concepção recusa a validade das justificativas feitas a partir de referenciais não europeus, quer sejam eles filosóficos, culturais, históricos, ou científicos, definindo conhecimento a partir de discursos dogmáticos.

A filosofia possibilita ao estudante uma reavaliação dos percursos identitários de grupos historicamente inferiorizados e marginalizados na história. E já que compreender os problemas da sociedade brasileira implica necessariamente levar em consideração a influência e os impactos do racismo sobre ela, é preciso que o ensino de filosofia perceba a importância de estreitar os diálogos com a educação antirracista. A razão, fonte suprema no pensamento filosófico, precisa redesenhar-se dentro de um modelo antirracista, conduzindo seu interlocutor a operar de forma justa e crítica. A filosofia, como nos diz Noguera (2014), opera com a razão a partir de princípios raciais, reforçando um falso lugar de inferioridade, sobretudo cognitiva, da população negra: "Em busca de uma razão aberta e afroperspectivista, a filosofia pode promover um aprendizado antirracista e edificante. É preciso, também, desafiar o racismo epistêmico, denunciá-lo, se colocar radicalmente contra ele em todos os aspectos" (NOGUERA, 2014, p. 98). 


\section{Afrocentricidade}

Tomando tais reflexões como mote para pensar o ensino da filosofia na educação, e as implicações do eurocentrismo na construção do saber mundial, é relevante a construção de outro modelo de paradigma que nos ajude a pensar a filosofia e a educação sem a marginalização dos saberes africanos, indígenas e ameríndios, retirando a Europa do centro do sistema mundo dos outros modelos epistêmicos.

A devastação colonial promoveu aos ocidentais o local hegemônico nos últimos cinco séculos da história do mundo, baseado em um projeto de dominação cultural, econômica, social e política, fazendo com que a humanidade tivesse a Europa como única referência de civilização. Essa referência, imposta pelo eurocentrismo e alicerçada pela colonização mental, impôs às outras civilizações um único paradigma de conhecimento, filosofia, ciência, arte e cultura, distorcendo suas identidades (cf. Fanon, 2006, 2008, por exemplo), pois passaram a se perceber através dos olhos do colonizador. Essa dimensão ajudou a concretizar o local de inferioridade dos povos colonizados, os quais foram deslocados de seus referenciais identitários. Daí ser necessário pensar estratégias para reintegrar os povos do continente africano a suas identidades, uma definição para que não mais se localizem e atuem à margem da experiência eurocêntrica.

Muito do que foi produzido epistemologicamente e estudado para esses fins foi orquestrado do ponto de vista dos interesses europeus, reservando às nações de África a localidade marginalizada na história.
Assim, com o objetivo de reorientar os africanos à centralidade de sua história, um conjunto de intelectuais - do continente e da diáspora africanas - desenvolve uma posição epistemológica que realoca os africanos como agentes de sua própria história.

O processo de recentralizar o legado desses povos cria a possibilidade de um novo capítulo dessa narrativa, de ser reescrita com seus valores protegidos, agindo na libertação da mente do africano. Essa perspectiva denomina-se Afrocentricidade. $\mathrm{O}$ professor Molefe Kete Asante é um dos principais articuladores desse paradigma. É através de sua figura que essa perspectiva ideológica toma visibilidade nos estudos de reintegração africana e se fundamenta o conceito e a possibilidade de que outros intelectuais possam desmistificar esse paradigma.

Para Asante, a afrocentricidade é definida da seguinte forma:

A ideia afrocêntrica refere-se essencialmente à proposta epistemológica do lugar. Tendo sido os africanos deslocados em termos culturais, psicológicos, econômicos e históricos, é importante que qualquer avaliação de suas condições em qualquer país seja feita com base em uma localização centrada na África e sua diáspora. Começamos com a visão de que a afrocentricidade é um tipo de pensamento, prática e perspectiva que percebe os africanos como sujeitos e agentes de fenômenos atuando sobre a sua própria imagem cultural e de acordo com seus próprios interesses humanos (ASANTE, 2009, p. 93).

A supremacia política, cultural, religiosa, tecnológica eurocêntrica dos últimos 
500 anos levou os povos dos seis continentes do mundo a interiorizarem a figura da Europa como aquela que precede a origem das civilizações. Pois bem, a consequência dessa percepção é que os povos desses continentes se tornam invisíveis e se tratando dos povos marginalizados pela colonização - os povos Africanos - essa invisibilidade ganha uma proporção muito maior, pois vem tangenciada pelo racismo. A proposta da Afrocentricidade trata justamente de "centrar" os povos africanos e de reorientálos na história, possibilitando-os encontrar sua localização e, a partir dela, construir sua própria "agência”.

A agência é a capacidade de dispor dos recursos psicológicos e culturais necessários para o avanço da liberdade humana [...]. Estou fundamentalmente comprometido com a noção que os africanos devem ser vistos como agentes em termos econômicos, culturais, políticos e sociais. $\mathrm{O}$ que se pode analisar em qualquer discurso intelectual é se os africanos são agentes fortes ou fracos, mas não deve haver dúvida de que essa agência existe. Quando ela não existe, temos a condição da marginalidade - e sua pior forma é ser marginal na própria história [...] Os Africanos têm sido negados no sistema de dominação racial branco. Não se trata apenas de marginalização, mas de obliteração de sua presença, seu significado, suas atividades e sua imagem. É uma realidade negada, a destruição da personalidade espiritual e material da pessoa africana (ASANTE, 2009, p. 94).
Nesse sentido, os africanos precisam ser vistos como agentes em todos os termos, representativos, subjetivos e epistêmicos. Segundo Asante (2009), os africanos têm sido negados no sistema de dominação racial e encontram-se em um estado permanente de "desagência", algo que não é complicado de imaginar se retornarmos o percurso histórico dos povos africanos desde as expansões territoriais da colonização. Quando consideramos questões de lugar, situação, contexto, e ocasião que envolvam participantes africanos, é importante observar o conceito de agência em oposição ao de desagência. Dizemos que se encontra desagência em qualquer situação na qual o africano seja descartado como autor ou protagonista em seu próprio mundo. (ASANTE, 2009, p. 95).

Dada a confusão comum instaurada pelo colonialismo —cujo objetivo é evitar que os povos africanos afirmem de forma positiva sua ética, seus valores e seu costume-, faz-se necessário informar a quem se refere este filósofo quando utiliza o termo "africano":

Não se trata de um termo essencialista, ou seja, não é algo que se baseie simplesmente no 'sangue' ou nos 'genes'. Muito mais do que isso, é um construto do conhecimento. Basicamente, um africano é uma pessoa que participou dos quinhentos anos de resistência à dominação europeia. Por vezes pode ter participado sem saber o que fazia, mas é aí que entra a conscientização. Só quem é conscientemente africano que valoriza a necessidade de resistir à aniquilação cultural, política e econômica - está corretamente na área da afrocentricidade. Não signi- 
fica que os outros não são africanos, apenas que não são afrocentrados. Os brancos do continente africano que nunca participaram da resistência à opressão, dominação ou hegemonia branca, são, com efeito, não-africanos. $\mathrm{O}$ fato de residir na África por si só não torna alguém africano. No final, argumentamos que a consciência, e não a biologia, determina nossa abordagem dos dados. (ASANTE, 2009, p. 103)

Ama Mazama, intelectual que compõe com Asante o quadro de pesquisadores do primeiro programa de doutorado em estudos afro-estadunidenses na Universidade de Temple, na Filadélfia, na qual Asante leciona ainda hoje, compartilha com ele a ideia de que a Afrocentricidade surge como um paradigma desafiador às propostas de dominação eurocêntricas responsáveis pelo desaparecimento do protagonismo dos povos africanos:

$\mathrm{Na}$ verdade, a afrocentricidade sustenta que, a menos que os africanos se disponham a reexaminar o processo de sua conversão intelectual, que ocorre sob o disfarce de "educação formal" continuarão sendo presa fácil da supremacia branca. O que se sugere é que, em vez disso, os africanos se reancorem, de modo consciente e sistemático, em sua própria matriz cultural e histórica, dela extraindo os critérios para avaliar a experiência africana. Assim, a afrocentricidade surgiu como um novo paradigma para desafiar o eurocentrismo, responsável por desprezar os africanos, destituí-los de soberania e torná-los invisíveis - até mesmo aos próprios olhos, em muitos casos (MAZAMA, 2009, p. 114).
A fim de reorientar cultural, social e politicamente os africanos e os intelectuais afrocentristas para trabalharem a partir dos seguintes postulados:

1. A humanidade começou na África e todos os subgrupos ou variedades humanas contemporâneas, isto é "raças", são ramificações da árvore genealógica na África [...].

2. Dada a premissa acima, os caucasianos são os descendentes de africanos que migraram para a Europa há cerca de cinquenta mil anos e, com a renovação da Idade do Gelo há quarenta mil anos sofreram alterações fenotípicas que os fizeram perder o pigmento e embranquecer. 3. A cultura humana, como a própria humanidade, começa na África e atinge seu mais alto estágio, isto é, civilização, primeiro na África.

4. A civilização moderna se origina no nordeste da África, nas terras chamadas Ta-Sehiti e Kemet, mais tarde denominadas Núbia e Egito, entre aproximadamente seis mil e treze mil anos atrás.

5. O judaísmo e o cristianismo são, ambos, correntes de religiosidade humana que emanam do vale do rio Nilo nos sentidos conceitual, simbólico, de doutrina e de organização.

6. A civilização greco-romana foi um entre muitos subprodutos da civilização do vale do rio Nilo, isto é, do Egito e da Etiópia.

7. A ciência e a tecnologia ocidental, assim como a religião originaram-se na África.

8. Houve uma série de viagens précolombianas da África até as Américas que se iniciaram aproximadamente em 1200 a.C. e continuaram até ao menos 140o.d.C. (FINCH III, 2009, p. 174-75). 
Os pensadores e pensadoras afrocêntricas partem dos pressupostos apresentados acima para entender que é perfeitamente possível, e necessário aos africanos se perceberem como agentes de sua história, pois está evidente que a história e cultura do continente africano não são dependentes da história da Europa e de sua avaliação sobre a África. O princípio organizador que determina a percepção de toda a realidade é a centralidade da experiência africana para os povos africanos. (MAZAMA, 2009, p. 117).

Nesse sentido, reafirmamos que o conceito de agência, apresentado acima, é de fundamental importância, pois é a partir dele que poderemos investigar, a título de exemplo, a agência da filosofia africana, ponto chave deste trabalho, nas questões mais relevantes de seu reconhecimento, retirando os africanos, assim, da condição de marginalidade em sua própria história. Para Molefi Kete Asante, Ama Mazama, e para qualquer intelectual que se intitule afrocentrista, uma perspectiva que marginalize os africanos em sua própria história é totalmente rejeitável.

Partindo desse pressuposto, Asante defende a importância de identificar a localização psicológica da autora, pesquisadora, intelectual que pretende trabalhar com os elementos que compõem a experiência africana. Desse modo, saberemos de que local parte o seu discurso e qual seu propósito frente a ele, se o mesmo serve como ferramenta emancipatória ou manutenção do discurso eurocêntrico de invisibilidade.

Nessa perspectiva, cabe ao afrocentrista proteger e defender os valores e elementos substanciais do continente, tendo em vista um projeto de humanidade que de fato respeite o modo de ser africano e o reintegre à história, libertando-os do exílio existencial.

Para Asante, a realização desse feito central só se dará quando todos os elementos linguísticos, psicológicos, sociológicos e filosóficos construírem sua agência, visando uma autêntica compreensão das características culturais africanas, (ASANTE, 2009). Uma das estratégias pode e deve vir pela via da Educação com o compromisso do ensino, por meio da agência educacional e devolutiva do legado africano, reintegrando um espólio histórico e epistêmico covardemente negado.

Assim, é preciso ter clareza das relações existentes entre filosofia, educação e cultura, visto que "Educação é fundamentalmente um fenômeno social cujo propósito é socializar o aprendiz; enviar uma criança para escola é prepará-la para tomar parte de um grupo social” (ASANTE, 1991, p. 170).

Utilizaremos, nas seções subsequentes deste capítulo, o paradigma afrocêntrico para evidenciar a filosofia afroperspectivista, teorizada por Renato Noguera, a partir do pensamento educacional brasileiro, a qual pretende proteger e defender os valores e elementos culturais do continente africano, tendo em vista um projeto de humanidade que de fato respeite as especificidades desse povo e seu legado filosófico, bem como oferecer uma alternativa ao modelo educacional vigente e responsabilizarse com ações na luta efetiva antirracial.

\section{Afrocentricidade e a Questão do Antigo Kemet \\ Seguindo a esteira dos trabalhos de Diop (1974) e de Obenga (1990), Asante nos}


chama a atenção para os seguintes fatos, embora a historiografia — fundamentada na concepção hegeliana, segundo a qual os povos africanos não possuíam históriaposicione o povo africano florescido antes da Era Cristã na "Pré-Histótia" da humanidade, encontramos evidencias extensivamente documentadas da presença dos povos africanos e pretos há pelo menos 6.000 anos na terra hoje conhecida como Egito (ASANTE, 1990). Esses povos, os egípcios33, "mantiveram sua perspectiva africana essencial em termos de mitos, simbolismos e ethos ao longo da história do país" e "apenas com a chegada à força dos gregos e posteriormente, no século VII, dos árabes, que o padrão mitopoético do Kemet experimentou mudanças." (ASANTE, 1990, p.52). Destaca-se nesses relatos duas questões fundamentais: (1) a anterioridade das civilizações clássicas africanas em relação às europeias e (2) a unidade cultural dos povos africanos, dos povos keméticos inclusive.

Sobre isso, Asante nos diz:

"Depois da conquista do Egito por Napoleão e Dominique Vivan Denon, imprimiu-se ao conhecimento da África uma orientação totalmente diferente. De repente, fomos apresentados a um novo campo da investigação humana, a egiptologia. Quando Champollion decifrou a escrita dos antigos egípcios, a Europa lançou-se à empreitada de desmontar a africanidade da história egípcia, bem como da história africana no que esta se relaciona ao valo do Nilo. O único rio do continente africano que se tornou parte da experiência europeia foi o Nilo. Foi

\footnotetext{
3 Doravante referidos apenas como keméticos.
}

como se a Europa o tivesse tirado da África, mililitro por mililitro, para despejá-lo na paisagem europeia. Todas as contribuições africanas do Vale do Nilo se tornaram contribuições europeias, e a Europa deu início à tarefa de confundir o mundo quanto à natureza do antigo Egito. Trata-se da maior de todas as falsificações (idem)

Essa falsificação se sustenta de forma mais persistente no mito da origem grega da civilização. Nesse sentido, Asante nos informa que “a África clássica deve ser o ponto de partida de todo discurso sobre o rumo da história africana. O Kemet está diretamente relacionado e ligado às civilizações Cush, Cayor, Peul, Iorubás, Akanas, Congo, Zulu e Bamum.” (1990, p.101).

\section{Questões Preliminares}

Uma pesquisa histórica preliminar nos mostrou que até meados do século XX o continente africano ainda era mantido como colônia de diversos países europeus, estando nessa condição como espólio da Grande Guerra, no que ficou conhecido como o Tratado de Berlim. Ainda hoje, diversos países africanos, como Gana, Congo e África do Sul, por exemplo, buscam autonomia política e econômica. Uma análise estrutural e crítica do ensino de filosofia nos permitiu perceber que apenas a partir da segunda metade do século XX o currículo, a transmissão do conhecimento e da cultura humanas através da experiência e categorias europeias passaram a ser oficialmente questionados.

O polímata senegalês Cheikh A. Diop e o filósofo e egiptólogo congolês Theophile 
Obenga, em 1974, apresentaram evidências conclusivas de que os antigos povos egípcios eram de mesma origem que aqueles da região do continente africano chamada hoje de África Subsaariana. E que estes denunciaram as inconsistências, preconceitos e disparates dos discursos coloniais ainda correntes e hegemônicos nas disciplinas de arqueologia, história, filosofia e egiptologia, acerca de uma alegada "inferioridade africana" e de uma "origem semítica/indoeuropeia dos egípcios faraônicos".

Nos Estados Unidos, desde 1980, filósofas e filósofos como Molefi Kete Asante, Ama Mazama e Clenora Hudson realizam pesquisas e produções de obras acadêmicas, relatando a permanência do conteúdo colonial na educação Americana e ressaltando a necessidade urgente de atualização do conteúdo do ensino nas instituições americanas.

Na África do Sul, filósofos como Mogobe Ramose (2011) e Simphiwe Sesanti (2018) também realizam esse trabalho de restauração da herança africana a partir dos próprios termos. Sesanti realizou em 2018 uma pesquisa em algumas universidades tradicionais de seu país e publica um artigo apresentando sua constatação da presença hegemônica no currículo acadêmico dos diversos interesses ocidentais no centro da educação africana e da imposição pela força da percepção e definição da vida eurocêntrica para todos os demais povos. O mesmo tendo sido feito por Ramose. Esses filósofos sul-africanos constatam - no currículo pedagógico e nas produções acadêmicas elaboradas depois de 22 anos de democracia do país - que a educação na África do Sul permanece colonial e eurocêntrica.
Em 1974, Cheikh Anta Diop publicou seu "The African Origin of Civilization: Myth or Reality", no qual argumenta que o antigo Egito foi uma civilização negra e que os antigos egípcios eram negros (1974, p. XIV). Sua insistência nesses detalhes se dá pelas persistentes tentativas dos historiadores e historiadoras eurocêntricos de projetar os antigos egípcios como brancos (1974, p. 27). Treze anos após a obra de Diop, surge a publicação do "Black Athena: The Afroasiatic Roots of Classical Civilization”, de autoria do estudioso britânico Martin Bernal, na qual Bernal aponta a civilização egípcia como fundamentalmente africana e como tendo presente em seus diversos períodos de apogeu faraós negros (Bernal, 1991, p. 242).

Pouco depois, Maulana Karenga (2004) produziu sua obra monumental, na qual apresenta a primeira abordagem acadêmica sobre antigo Egito a partir de seu próprio contexto e perspectiva filosófica. Desde então, filósofos como Theóphile Obenga e Molefi Asante, para citar alguns, têm dedicado considerável tempo abordando o tema do Kemet. A contribuição dos trabalhos dessas pensadoras e pensadores é que através de suas publicações encontramos uma das mais antigas discussões sobre o bem e o mal de que se tem registros na história da humanidade, presentes nas concepções de Maat e que perdurou aproximadamente quatro mil anos. A leitura dos trabalhos nos permite perceber que considerar a investigação filosófica da produção Kemética não implica considerar tratar-se de uma sociedade perfeita. Como qualquer povo, o Kemet teve seus períodos de instabilidade, disputas por liderança, tentativas de golpes 
de Estado e outras intrigas internas. Sua relação direta com o ensino de filosofia chama a atenção para o fato de que a separação do antigo Egito do resto do continente africano representa o estabelecimento geopolítico colonial da perspectiva eurocêntrica do século dezesseis.

No Brasil, dos pouco mais de 500 anos desde sua constituição, somente 131 são de emancipação dos povos africanos e indígenas, sobre os quais há pouco mais de 50 anos teorias racistas como a da eugenia ainda eram desenvolvidas, aceitas e veiculadas nas universidades do país.

$O$ que esses dados reunidos nos permitem perceber é que há menos de um século os povos africanos e ameríndios ainda eram compreendidos em todo o globo pelas lentes da mesma perspectiva racista e colonial europeia do século dezesseis. E que os reflexos desse fenômeno podem ser constatados nos currículos escolares e acadêmicos das universidades ao redor do globo.

No que diz respeito ao Brasil, apenas a partir do início do século XXI, mais precisamente no ano de 2003, que o currículo brasileiro passou a ser oficialmente questionado e, pela força da lei, vem sendo atualizado. E mesmo passada mais de uma década das referidas medidas, o conteúdo curricular das instituições de ensino e dos materiais didáticos brasileiros permanece colonial e eurocêntrico. O que culminou na promulgação da Lei 10.639/03, fruto dos diversos movimentos de resistência à opressão do racismo, como o Movimento Negro, que promoveu alterações na Lei de Diretrizes e Bases da Educação Nacional, estabelecendo que os estudos de História e Cultura Afro-Brasileira, Africana e Indígena sejam obrigatórias em todas as modalidades de ensino e níveis de educação, e permitiu o estabelecimento do Plano Nacional para Implementação das Diretrizes Curriculares Nacionais para Educação das Relações Étnico-Raciais, segunda a qual toda a população brasileira é responsável pela promoção do combate ao racismo no Brasil.

Desde 2013 o filósofo brasileiro Renato Noguera vem questionando o fenômeno que ele chamou de "Tabu da Filosofia”, o que promoveu uma diversificação e uma abertura de espaço para perspectivas diferentes daquelas do pensamento Ocidental para o conteúdo da produção acadêmica em filosofia.

Seguindo na esteira de filósofas e filósofos que problematizam a concepção hegemônica de filosofia no mundo, Renato Noguera problematizou essa concepção no Brasil e conceituou o fenômeno mundial do racismo epistêmico como ele é aqui sustentado nos ambientes acadêmicos, que se manifesta na predominante defesa do nascimento grego da Filosofia. Um conjunto de pesquisadoras e pesquisadores vem desde então contribuindo e ampliando o debate e a constituição de uma nova "coreografia do pensamento", para a qual é fundamentalmente importante a revisão e o questionamento das geopolíticas estabelecidas de forma hegemônica, com a finalidade de rechaçar as cartografias e hierarquizações que insistem em posicionar a Europa como centro da construção histórica humana e a intitular a construção grega dos pensamentos filosófico e científico como (1) originais, (2) frutos de um milagre e (3) marco temporal do nascimento da razão e sua instrumenta- 
lização para o uso do pensamento em toda a humanidade.

A reprodução imprudente desse discurso falacioso no Brasil como algo "objetivo", "universal" e inquestionável tem prolongado em nossa cultura e reproduzido em nossa sociedade o mito da superioridade europeia e o relato de sua experiência como início da história e do pensamento de toda a humanidade.

Desde a formulação do conceito filosófico da Afrocentricidade, um número crescente de pesquisadoras e pesquisadores tem contribuído para a ampliação desse debate em todo o mundo. Fizemos um levantamento de quantas obras se dedicaram especialmente aos avanços que giram em torno de pensar filosofia a partir de outros paradigmas após o estabelecimento do "Tabu da Filosofia" pelo filósofo Renato Noguera. Alguns trabalhos versam sobe o tema referente à afrocentricidade e/ou Egito Antigo, seja o assunto propriamente dito, seja análises de obras sobre filosofia africana ou teses de críticas ao epistemicídio e sua eficácia no silenciamento das epistemologias africanas. São eles:

- A monografia Latu Senso de Alexandre de Lourdes Laudino, intitulada: A Filosofia como modo de vida: um estudo comparativo dos ensinamentos de Pthahotep e Epicteto, de 2013;

- A monografia de Alexsandro Alves da Maia, intitulada: Afrocentricidade: A possibilidade das práxis filosóficas em sala de aula, de 2015;
- A dissertação de Mestrado de Luiz Thiago Freire Dantas, intitulada: Filosofia Africana no Ensino Médio: Por uma descolonização curricular, de 2015;

- O ensaio de Jayro Pereira de Jesus, Miriam Cristiane Alves, Danielle Scholz, intitulada: Paradigma $d a$ Afrocentriciade e uma nova concepção de humanidade e saúde coletiva: relação entre saúde mental e racismo;

- $\mathrm{O}$ artigo de Mauricio Silva, intitulado: Afrocentricidade: Um conceito para a discussão do currículo escolar e a questão étnico-racial na escola, de 2016;

- A tese de doutorado de Ricardo Matheus Benedicto, intitulada: Afrocentricidade, Educação e Poder: Uma crítica Afrocêntrica ao Eurocentrismo no Pensamento Educacional Brasileiro, de 2016;

- A dissertação de mestrado de Katiúscia Ribeiro Pontes, intitulada: Kemet, Escola e Arcadeas a Importância da Filosofia Africana no combate ao Racismo Epistêmico e a Lei 10639/o3, de 2017;

- A dissertação de mestrado de Ellen Aparecida de Araújo Rosa, intitulada: Rekhet - A Filosofia Antes da Grécia: Colonialidade, Exercícios Espirituais e o Pensamento Filosófico na Antiguidade, de 2017;

- A tese de doutorado de Luiz Thiago Freire Dantas com o título: Filosofia desde África perspectivas Coloniais, de 2018; 
- A Nota de Pesquisa de Valter Duarte Moreira Junior, intitulada: Sobre o resgate e a difusão da Cultura Africana, de 2018.

Enquanto os currículos, manuais didáticos e um largo volume de trabalhos acadêmicos na área ainda afirmam a certidão de nascimento grega da filosofia, entre os séculos V e III a.E.C., as evidências factuais revelam que esse tipo de investigação foi realizada onde quer que o ser humano tenha se estabelecido e se instalado, como apresentado pelo português José Nunes Carreira, pelo sul-africano Mogobe Ramose, pelo yanomami Davi Kopenawa e pelo italiano Robert Bernasconi, para citar alguns, sendo possível ainda encontrar relatos e reflexões registradas por escrito em grande volume de documentos, monumentos e artefatos no continente africano, especialmente na região conhecida como o Vale do Nilo —constituídos pelo menos dois milênios antes da constituição do pensamento filosófico grego-, seguida e desenvolvida por outros povos africanos, como é o caso dos povos cushitas, do atual Sudão, cuja escrita e um volumoso corpus literário permanecem não decifrados.

\section{Considerações Finais}

Fizemos nesse trabalho uma breve apresentação do paradigma Afrocêntrico, um levantamento bibliográfico qualitativo sobre a produção acadêmica de filosofia e constatamos a resiliência do pensamento racista e colonial reproduzido nos ambientes educacionais pela força do hábito. Constatamos também que a reinvindicação de uma narrativa da história dos povos africanos, indígenas e ameríndios enquanto sujeitos e agentes da experiência humana tem recebido mais espaço nos periódicos acadêmico-filosóficos. Contudo, apesar do caudaloso renascimento cultural africano, indígena e ameríndio presente nessas produções, dentre essas produções, a questão do Kemet e sua relação com os demais povos africanos permanecem represadas nos sinópticos espaços dos verbetes, ou em um número bastante circunscrito de produções.

Apesar de nosso apreço pela posição acadêmica com as filosofas e filósofos do pensamento decolonial de sustentar os objetivos centrais de identidade e emancipação cultural em seus projetos de produção de conhecimento, não podemos deixar de notar que, como observa o filósofo sulafricano C. T. Keto (1989, p. 23), “o foco seccionalista na assim chamada 'África Subsaariana', ou 'África Tropical', ignora os elementos da unidade cultural antes do dessecamento do Sael no tempo histórico e [antes] do advento do Islam no sétimo século da Era Corrente”. Em outras palavras, essa postura vai tanto de encontro às evidências da origem africana dos povos do antigo Egito, quanto da unidade cultural de todos os povos daquele continente. De acordo com Asante:

A anterioridade das civilizações clássicas africanas deve ser considerada em qualquer pesquisa Africológica. As referências clássicas são necessárias enquanto estruturas basilares para discutir o desenvolvimento dos fenômenos culturais africanos. Sem tais pontos de referência, a maior parte da pesquisa 
aparecerá desconexa, sem continuidade histórica, discreta e isolada, incidental e não orgânica. (ASANTE, 1990, p. 12)

$\mathrm{O}$ que erige em nós um questionamento preliminar: Por quais razões? Ou ainda: Há nessa constatável falta de atenção e nesse aparente desprezo uma das manifestações da dúvida gerada pela colonialidade acerca da validade da filosofia kemética? Essa questão provoca em nós questões subsequentes: se podemos reconhecer a existência da filosofia kemética, o que a constitui? O que há nela de semelhante, ou dessemelhante, da filosofia produzida nos demais países do continente africano? Talvez essas questões nos levem a responder aquela que nos parece ser a mais importante: Tem a filosofia kemética algo de valioso a nos dizer?

Nossa preocupação dentro desse debate repousa sobre o fato de que trazer o Egito (Kemet, ou Kmt) para o currículo filosófico é tanto um ato decolonial quanto afrocentrado. Em outras palavras, ele é tanto uma obrigação moral e um ato humanista quanto um procedimento para dar subsídios a um currículo que favoreça a pluriversalidade de perspectivas, a diversidade etnicorracial e contribua para desconstrução das desigualdades sócio-culturais e da ignorância generalizada acerca da história da própria humanidade. Constituindo juntos imperativos anteriores ao próprio cumprimento da Lei 10.639/o3, de combate à ideologia do racismo antinegro e do das práticas sistemáticas do epistemicídio na sociedade brasileira. Juntos, eles configuram uma possibilidade real e interessante para combater o racismo antinegro, contribuindo para que os povos descendentes de africanos, indígenas e ameríndios reconheçam na produção histórica e cultural do Brasil sua participação ativa e direta.

Está longe de nossas pretensões apresentarmos aqui respostas categóricas, rápidas, ou reducionistas, que em geral não levam em consideração toda a complexidade das relações sociais, políticas, econômicas e inclusive ideológicas dentro das quais esse fenômeno se manifesta. Como já dissemos em outros trabalhos, tampouco nos referimos a pessoas, ou quaisquer instituições. Nesse sentido seguimos os pressupostos de pensadores como Deleuze, isto é, os alvos de nossas reflexões são as ideias, principalmente as "ideias prontas", aspecto sobre o qual é importante sublinharmos em acréscimo que os rumos da afrocentricidade encontram-se abertos e que os caminhos até agora explorados são pontos de partida, não uma linha de chegada.

\section{Referências}

AMIN S. Eurocentrism. New York, USA: Monthly Review, 1989.

ASANTE, Molefi K. Afrocentric idea in education. In: The Journal of negro. Vol. 6o. n. 2, 1991, pp.170-18o. 
. Kemet, Afrocentricity and Knowledge. Africa World Press: New Jersey, 1990.

. Afrocentricidade: Notas sobre uma posição disciplinar. In: Elisa L. Nascimento (org.). Afrocentricidade: uma abordagem epistemológica inovadora. São Paulo: Selo Negro, 20o9, p. 93-110.

DIOP, C.A. The African Orogin of Civilization: Myth or Reality. NY: Lawrence\& Hill, 1974. FANON, Frantz. Os condenados da terra. Tradução Enilce Albergaria Rocha, Lucy Magalhães. Juiz de Fora: UFJF, 2006.

Pele negra, máscaras brancas. Tradução Renato da Silveira. Salvador: UFBA, 2008.

FINCH III, Charles S. A Afrocentricidade e Seus Críticos. In: Elisa Larkin. Nascimento (Org.). Afrocentricidade: uma abordagem epistemológica inovadora. São Paulo: Selo Negro, 2009. p. 167-177.

JOHN, V. \& SOSIBO, K. Leaders of the Rhodes Rebellion. MALI \& GUARDIA 2015.

KARENGA, Maulana. Maat, the Moral Ideal in Ancient Egypt: an study in classical african ethics. New York: Routledge Press, 2004.

KETO, C. T. The Africa Centred Perspective of History and Social Sciences. In: The twenty first century. Blackwood, USA: K.A. Publications, 1989.

MALDONADO-TORRES, N. "Frantz Fanon and the Decolonial Turn" In Psicology: From Modern/Colonial Methods to the Decolonial Attitude. In: South Africa Journal of Philosophy, 47(4), 2017, pp. 432-441.

MAZAMA, Ama. A Afrocentricidade Como um Novo Paradigma. In: Elisa Larkin. Nascimento (Org.). Afrocentricidade: uma abordagem epistemológica inovadora. São Paulo: Selo Negro, 2009. p.111-127.

MEIER, Celito. Filosofia: por uma inteligência da complexidade. 1. ed. Belo Horizonte: Fax Editora, 2010.

MAZAI, Norberto. Trajetória do Ensino de Filosofia no Brasil. Revista Disciplinarum Scientia. Série: Ciências Sociais e Humanas, Santa Maria. 2001.

MUDIMBE, V. Y. The invention of Africa: Gnosis, Philosophy and Order of Knowledge. London, UK: James Curre, 1988.

NDOLOVU-GATSHENI. Why Decoloniality In The 21st Century? The Thinker, 48, 10-15, 2013, p.13.

NOGUERA, Renato. O Ensino de Filosofia e a Lei 10.639. Rio de Janeiro: Pallas: Biblioteca nacional, 2014 .

OBENGA, Théophile. La philosophie africaine de la période pharaonique (2780-330 a. C.), Paris: L'Harmattan, 1990. 
RAMOSE, Mogobe. Sobre a legitimidade e o estudo da filosofia africana. Trad. Dirce Eleonora Nigro Solis; Rafael Medina Lopes; Roberta Ribeiro Cassiano. In: Ensaios Filosóficos, Volume IV, 2011.

SESANTI, Simphiwe. Teaching Ancient Egyptian Philosophy (Ethics) and History: Fulfilling a Quest for a Decolonised and Afrocentric Education. In: Educational Research for Social Change (ERSC). Vol 7, Jun 2018, p. 1-15.

Recebido em: 05/06/2019

Aprovado em: 31/10/2019 